\title{
High Temperature Effects on Seedling Emergence and Embryo Protein Synthesis of Sorghum
}

\author{
H. J. Ougham, J. M. Peacock, J. L. Stoddart, and P. Soman
}

\section{ABSTRACT}

High soil temperatures $\left(>45^{\circ} \mathrm{C}\right)$ inhibit the field emergence of sorghum [Sorghum bicolor (L.) Moench] in the semiarid tropics. The objective of this study is to demonstrate that the measurement of embryo protein synthesis (EPS) is a convenient and rapid technique for the assessment of sorghum emergence at high soil temperatures. Two experiments were conducted, one using four landrace accessions and another using 14 commercially available lines. Seedling emergence was measured in a large water bath containing a series of soilfilled clay pots. The temperature of the soil in the pots could be regulated $\left(35-50^{\circ} \mathrm{C}\right)$ using infrared lamps. Protein synthesis was measured by incubating embryo-containing half-seeds with ${ }^{14} \mathrm{C}-\mathrm{la}$ beled amino acids at different temperatures $\left(35-40^{\circ} \mathrm{C}\right)$; the resulting labeled proteins were extracted for counting. The relative rankings of the landraces with respect to EPS and emergence demonstrated that the EPS technique clearly distinguished between lines that were able or unable to emerge at $50^{\circ} \mathrm{C}$. However, with the commercially available lines, despite the agreement between the ranking of EPS and emergence, two lines diverged from this relationship, which is attributed to the greater complexity of the overall emergence process.

Additional Index Words: Emergence (seedlings), Establishment, Protein synthesis (embryos), Soil temperature, Sorghum bicolor (L.) Moench.

DoOR CROP establishment is one of the major problems limiting the production of sorghum in the semiarid tropics. Soil temperatures $>45^{\circ} \mathrm{C}$ are known to influence sorghum germination and subsequent plumule extension, which affects seedling emergence resulting in sparse and uneven stands (Peacock, 1982). In India, West Africa, and southern Africa, soil surface temperatures in farmers' fields commonly exceed $45^{\circ} \mathrm{C}$ and temperatures as high as $60^{\circ} \mathrm{C}$ have been recorded (Peacock and Ntshole, 1976; Peacock, 1977; Soman et al., 1981). Genetic variation in emergence capability under high soil temperatures has been shown to exist (Peacock, 1982), and lines capable of emerging through soil at temperatures of $55^{\circ} \mathrm{C}$ have been identified (Wilson et al., 1982). The various techniques developed to study the germination and emergence responses of cereals to high soil temperatures have recently been evaluated by Soman and Peacock (1985). In the same paper, a technique to screen sorghum lines for emergence ability through a hot soil surface, where soil water and surface crusting are not limiting, is described. In the same year, Ougham and Stoddart (1985) demonstrated that the capacity of sorghum lines to germinate

H.J. Ougham and J.L. Stoddart, Welsh Plant Breeding Stn. (WPBS), Aberstwyth, Wales; and J.M. Peacock and P. Soman, Int. Crops Res. Inst. for the Semi-Arid Tropics (ICRISAT), Patancheru P.O., - Andhra Pradesh, India. Contribution from WPBS and ICRISAT.

This research was partly supported by U.K. Overseas Development Administration's Res. Grant no. R3801. Submitted as ICRISAT Journal Article no. 601. Received 23 July 1986. "Corresponding author.

Published in Crop Sci. 28:251-253 (1988). at high temperatures $\left(>40^{\circ} \mathrm{C}\right)$ was clearly related to the temperature sensitivity of de novo protein synthesis in the embryo, as is also the case in maize (Zea mays L.) (Riley, 1981a, b; 1984). This paper documents that seedling emergence at high temperature is related to embryo protein synthesis (EPS), which offers a practical method to distinguish sorghum lines for their ability to emerge under these adverse conditions.

\section{MATERIALS AND METHODS \\ Plant Materials}

Two experiments were conducted in which EPS and seedling emergence percentage were determined at a range of temperatures. The seeds of all genotypes were from a contemporary multiplication in the same field at ICRISAT Center, Patancheru, India, grown and harvested in the dry, postrainy season of 1983 .

In Exp, 1, four landrace lines (IS 1054, IS 2146, IS 2282, and IS 6118) selected on the basis of contrasting performance at high temperatures were screened. The first two lines are susceptible and the latter two lines are resistant to high temperatures during emergence.

In Exp. 2, 14 commercially available breeding lines were used. These consisted of three cultivars ('SPV 354,' 'SPV 386,' and 'CSV 5') and three hybrids together with their respective parents. In each case, the name of the hybrid is followed by first, its male parent; second, its female parent; and third, the associated B (maintainer) line; i.e., 'CSHI,' IS 84, CK 60A, CK 60B; 'CSH5,' CS 3541, 2077A, 2077B; 'CSH 6,' CS 3541, 2219A, 2219B.

\section{Measurement of Emergence at High Soil Temperatures}

The apparatus for measurement of emergence at high soil temperatures consisted essentially of a large water bath containing a series of soil-filled clay pots $30 \mathrm{~cm}$ long and $10 \mathrm{~cm}$ in diameter. This arrangement ensured that the soil in the pots was kept at an optimum moisture content at every temperature (Soman and Peacock, 1985). The soil in the pots was heated by infrared lamps fitted to a movable frame above the tank. The temperature of the soil surface was regulated by adjusting the height of the lamps, so that soil temperatures in the range of 35 to $50^{\circ} \mathrm{C}$ diurnal maximum (measured at the $2-\mathrm{cm}$ depth) could be achieved.

Ten seeds of uniform size for each cultivar were sown at a 5-cm depth in each pot. The experimental design was a randomized block with four replicates. Emergence of visible seedlings was recorded $4 \mathrm{~d}$ after sowing at 35, 40, 45, and $50^{\circ} \mathrm{C}$.

\section{Measurement of Protein Synthesis}

Ten embryo-containing half-seeds (see Ougham and Stoddart, 1985) were surface-sterilized in sodium hypochlorite 
solution ( $160 \mathrm{mM}$ active $\mathrm{Cl}$ ) for $20 \mathrm{~min}$, thoroughly rinsed, and blotted dry. They were incubated for $16 \mathrm{~h}$ at the appropriate temperature in $1 \mathrm{~mL}$ of $20 \mathrm{mM}$ tris- $\mathrm{HCl}$ (pH 7.5), 5 $\mathrm{mM} \mathrm{MgCl}$, containing $0.30 \mathrm{~g}$ chloramphenicol L' ' (2-2Dichloro-N-[2-hydroxy-1-(hydroxymethyl-2-(4-nitrophenyl) ethyl]acetamide) and $37 \mathrm{~Bq} \mathrm{~L}$ ' [U-145-amino acid mixture (Amershàm Int., Buckinghamshire, England, catalogue no. CFB 104)] in small glass vials plugged with cotton wool to prevent excessive evaporation during the course of the experiment. After incubation, the seeds were thoroughly rinsed in deionized water, blotted dry, and homogenized in $1 \mathrm{~mL}$ of distilled water per 10 half-seeds. Samples (100-300 $\mu \mathrm{L})$ of homogenate were applied to nitrocellulose filter disks (pore size $45 \mu \mathrm{m}$ ), with a glass-fiber disk (Whatman, grade GF/A) placed above each nitrocellulose disk as a prefilter. This procedure obviated the requirement for a centrifugation step to remove particulate material. The glass-fiber/nitrocellulose disk combinations were washed twice with $5 \mathrm{~mL}$ of distilled water to remove unbound radioactivity, and the nitro-cellulose disks were air-dried and counted in a toluene/Triton $\$$ PPO (2,5-diphenyloxazole) scintillation cocktail consisting of toluene/Triton $(2: 1, \mathrm{v} / \mathrm{v})$ containing $4 \mathrm{~g}$ PPO L ', using an LKB RackBeta (Wallace OY, Turku, Finland) liquid scintillation counter. Nitrocellulose binds protein but not free amino acids. Therefore, the measured amount of radioactivity bound to each disk was proportional to the amount of de novo protein synthesis that occurred in the seed batch during the incubation period.

The absolute values of radioactivity incorporated per halfseed vary greatly according to seed size, specific radioactivity of the amino acid mixture used, etc. For comparative purposes, results were thus expressed as percentage decrease in radioactive amino acid incorporation over a given temperature range. Since percentage drop is calculated from the mean EPS at each temperature, this reduces the available values to one data point for each temperature for any given line. Each data point is the mean of only two replicates; therefore, we are unable to provide any meaningful statistical analysis for Table 2. However, each replicate contained a large number of half-seeds, as a result values were quite accurate and the errors are small. The incorporation of radioactive amino acid at $35^{\circ} \mathrm{C}$ was considered to be $100 \%$, since no line tested has shown heat-sensitivity at or below this temperature. A more detailed discussion of the application and possible limitations of the procedure is given by Ougham and Stoddart (1985). For each seed sample, at least two batches of 10 embryo-containing half-seeds were tested at each temperature $\left(35,40,45\right.$, and $\left.50^{\circ} \mathrm{C}\right)$. At least two different volumes of seed homogenate were applied to disk combinations for each batch, and each nitrocellulose disk was counted twice to allow for anomalies in disk orientation within the counting chamber.

\section{RESULTS AND DISCUSSION}

\section{Emergence and Protein Synthesis}

Table 1 shows the percentage emergence of the four lines tested in Exp. 1, and 14 lines tested in Exp. 2 at four screening temperatures from 35 to $50^{\circ} \mathrm{C}$. The corresponding values for EPS (disintegrations per second [dps] radioactive amino acid incorporated per embryo-containing half-seed as a percentage of the incorporation measured at $35^{\circ} \mathrm{C}$ ) are given in Table 2 .

It should be noted that the temperature range examined in these studies on EPS was lower than that used to assess emergence capability. This was due to the difference in the actual temperature to which the
Table 1. Effect of soil temperature on percentage sorghum seedling emergence.

\begin{tabular}{|c|c|c|c|c|}
\hline \multirow[b]{2}{*}{ Line } & \multicolumn{4}{|c|}{ Soil temporature } \\
\hline & $35^{\circ} \mathrm{C}$ & $40^{\circ} \mathrm{C}$ & $15^{\circ} \mathrm{C}$ & $50^{\circ} \mathrm{C}$ \\
\hline \multicolumn{5}{|c|}{ Exp. 1 } \\
\hline $\begin{array}{l}\text { IS } 1054 \\
\text { IS } 2146 \\
\text { IS } 2282 \\
\text { IS } 6118\end{array}$ & $\begin{array}{r}100 \\
100 \\
100 \\
80\end{array}$ & $\begin{array}{l}60 \\
60 \\
90 \\
90\end{array}$ & $\begin{array}{r}0 \\
50 \\
80 \\
70\end{array}$ & $\begin{array}{r}0 \\
0 \\
20 \\
60\end{array}$ \\
\hline \multicolumn{5}{|c|}{ Exp. 2} \\
\hline $\begin{array}{l}\text { CK 60A } \\
\text { CK 60B } \\
\text { IS } 84 \\
\text { CSH 1 } \\
2077 A \\
2077 B \\
\text { CS 3541 } \\
\text { CSH 5 } \\
2219 A \\
2219 B \\
\text { CSH 6 } \\
\text { SPV 386 } \\
\text { SPV 354 } \\
\text { CSV 5 } \\
\text { Mean } \\
\pm \text { SE }\end{array}$ & $\begin{array}{l}93 \\
83 \\
88 \\
93 \\
80 \\
78 \\
90 \\
88 \\
90 \\
73 \\
88 \\
85 \\
98 \\
48 \\
83.9 \\
3.3\end{array}$ & $\begin{array}{l}93 \\
83 \\
80 \\
80 \\
90 \\
70 \\
90 \\
75 \\
90 \\
93 \\
93 \\
95 \\
85 \\
90 \\
86.2 \\
2.0\end{array}$ & $\begin{array}{l}83 \\
93 \\
78 \\
85 \\
80 \\
90 \\
78 \\
68 \\
90 \\
70 \\
83 \\
90 \\
88 \\
65 \\
81.5 \\
2.4\end{array}$ & $\begin{array}{l}65 \\
75 \\
60 \\
63 \\
85 \\
13 \\
83 \\
73 \\
85 \\
50 \\
70 \\
80 \\
80 \\
50 \\
66.6 \\
5.2\end{array}$ \\
\hline
\end{tabular}

Table 2. Effect of temperature on embryo protein synthesis of sorghum seeds expressed as percentage decrease in protein oynthesis for each of the temperature intervals $35-40$ and $40-45^{\circ} \mathrm{C}$.

\begin{tabular}{lcc} 
& \multicolumn{2}{c}{ Temperature intervals } \\
\cline { 2 - 3 } Line & $35-40^{\circ} \mathrm{C}$ & $40-45^{\circ} \mathrm{C}$ \\
\hline & Exp. 1 & \\
IS 1054 & 35 & 16 \\
IS 2146 & 16 & 18 \\
IS 2282 & 8 & 36 \\
IS 6118 & 7 & 42 \\
& Exp. 2 & \\
CK 60A & 27 & 19 \\
CK 60B & 22 & 16 \\
IS 84 & 50 & 15 \\
CSH 1 & 47 & 21 \\
2077A & 9 & 47 \\
2077B & 24 & 20 \\
CS 3541 & 36 & 34 \\
CSH 5 & 19 & 28 \\
2219A & 38 & 10 \\
2219B & 59 & 10 \\
CSH 6 & 34 & 36 \\
SPV 386 & 2 & 27 \\
SPV 354 & 0 & 45 \\
CSV 5 & 23 & 35 \\
\hline
\end{tabular}

seeds were exposed during the course of the experiments. During the 16-h incubation period in which the seeds imbibed radioactive amino acids, they were immersed in an aqueous solution at the specified temperature. Conversely, seeds germinating in soil-filled pots as described by Soman and Peacock (1985) were in contact with soil in which the temperature varied diumally and were also dependent upon depth (i.e., distance from the infrared heat source). Thus, the temperatures specified were measured at a soil depth of 2 $\mathrm{cm}$ and were 3 to $5^{\circ} \mathrm{C}$, higher than the mean temperature experienced by the germinating seeds. Correlations, therefore, between the two sets of data reflect the association between the relative susceptibilities of the two characters (EPS and seedling emergence) to 
elevated temperature, and are not applicable to an absolute determination of the temperatures likely to result in unacceptably poor performance under field conditions.

Rankings for EPS determined on the basis of percentage' decline in synthesis between 35 and $40^{\circ} \mathrm{C}$ showed the greatest variation between heat-susceptible and heat-tolerant lines in this temperature range and have been discussed previously (Ougham and Stoddart, 1985). With respect to percentage emergence, lines were ranked according to mean emergence percentage at $50^{\circ} \mathrm{C}$ as a percentage of the maximum emergence obtained within the temperature range of 35 to $50^{\circ} \mathrm{C}$.

Ougham and Stoddart (1985) showed that the degree of correlation between temperature sensitivity for germination and that for EPS was very high. The work of Riley (1981a, b; 1984) demonstrated that EPS is also the heat-sensitive process limiting the germination of maize at high temperatures. This correlation may prove applicable for all cereal crops where emergence at elevated temperatures is a problem.

The rapid laboratory technique reported here for the measurement of protein synthesis by germinating sorghum embryos at a range of temperatures could, therefore, be used as a screening technique to assess the temperature susceptibility of a sorghum seed sample during germination and thus to predict its likely field performance at elevated temperatures. As shown in this study, seedling emergence and EPS correlate with each other. However, two lines (2077B and 2219A) displayed highly anomalous behavior that reflects the greater complexity of the overall emergence process compared with germination. Although successful germination requires a number of biochemical processes, emergence depends not only on the physiological process for germination but also on the capacity of the seedling to elongate and emerge through the surrounding soil. During this phase, elevated soil temperatures may exert an additional adverse effect on a number of seedling emergence parameters.

Experiment 1, which investigated four landrace lines selected on the basis of contrasting emergence performance at elevated temperature, demonstrated that the EPS screening technique clearly distinguished between lines of sorghum that were tolerant or susceptible to elevated temperatures.

\section{Parent-Hybrid Comparison}

In Exp. 2, which compared emergence and embryo protein synthesising capacity by hybrid sorghums (CSH 1, CSH 5, and CSH 6) and their respective parents, the performance of a given hybrid was generally intermediate between those of its parents. This contrasts with earlier observations during the development of the screening technique (Ougham and Stoddart, 1985), that hybrids exhibited both a lower absolute level of EPS at all temperatures and also a greater susceptibility to elevated temperatures. The explanation for this apparent inconsistency may be due to the location of seed production of the seed lots used for the two series of experiments. In the first study, hybrid seed was obtained from commercial seed suppliers, whereas for experiments reported here, hybrid seed was produced at the ICRISAT Center, Patancheru, and harvested simultaneously with seed of the parental lines grown under similar environmental conditions. Two consequences of this difference in location of seed production are apparent. First, the hand pollination of panicles used in the latter instance resulted in a low seed number per mature panicle compared with the seed number normally achieved during commercial hybrid seed production. Second, production of hybrid seed and seed of parental lines in the same environment during the same growing season would minimize the variation between seed lots due to environmental factors.

\section{CONCLUSIONS}

The results of this study show that the sensitivity of EPS to elevated temperatures can be used as a convenient and rapid screening technique for the assessment of sorghum emergence at high soil temperatures. However, despite the general agreement between EPS and percentage seedling emergence, two lines showed anomalous behavior. This finding emphasizes the need for further detailed study of the biochemical and physiological processes involved in sorghum seedling emergence before breeders and the seed industry accept this as a practical screening technique.

\section{ACKNOWLEDGMENTS}

The excellent technical assistance of Ms. Teresa Davies and Mr. B. Raja Reddy is gratefully acknowledged.

\section{REFERENCES}

Ougham, H.J., and J.L. Stoddart. 1985. Development of a laboratory screening technique, based on embryo protein synthesis, for the assessment of high-temperature susceptibility during germination of Sorghum bicolor. Exp. Agric. 21:343-355.

Peacock, J.M. 1977. The weather at Content Farm, Sebele, Botswana. Dryland Farming Research Scheme (DLFRS) Botswana. p. 85-87. In Interim scientific report phase II. DLFRS, Government Printer, Gaborone, Botswana.

-1982. Response and tolerance of sorghum to temperature stress. p. 143-160. In L.R. House et al. (ed.) Sorghum in the eighties. Proc. Int. Symp. Sorghum, Patancheru, India. 2-7 Nov. 1981. ICRISAT. Pantancheru. India.

---, and M.R. Nishole. 1976. The effect of row spacing and plant population on the growth, development, grain yield, microclimate and water use of Sorghum bicolor cv. 65D. p. 32-44. In Initial annual report phase II. Dryland Farming Research Scheme (DLFRS), Gaborone. Botswana. Government Printer, Gaborone. Botswana.

Riley, G.J.P. 1981a. Effects of high temperature on the germination of maize (Zea may's L.). Planta 151:68-75.

-1981b. Effect of high temperature on protein synthesis during germination of maize (Zea mays L.). Planta 151:75-80.

--.. 1984. Effect of high temperature on RNA synthesis during germination of maize (Zea mays L.). Plant Sci. Lett. 35:201-205.

Soman. P.. F.R. Bidinger, J.M. Peacock, and T.S. Walker. 1981. Seedling establishment-a preliminary survey taken up in Aurepally during Kharif 1981. ICRISAT Int. Rep. ICRISAT, Patancheru. India (restricted circulation).

- . and J.M. Peacock. 1985. A laboratory technique to screen seedling emergence of sorghum and pearl millet at high temperature. Exp. Agric. 21:335-341.

Wilson, G.L., P.S. Raju, and J.M. Peacock. 1982. Effect of soil temperature on seedling emergence in sorghum. Indian J. Agric. Sci. 52:848-851. 